\title{
ChemComm
}

Check for updates

Cite this: Chem. Commun., 2018, 54, 3166

Received 25th January 2018, Accepted 5th March 2018

DOI: $10.1039 / \mathrm{c} 8 \mathrm{cc} 00636 a$

rsc.li/chemcomm

\section{Carbon dioxide-based facile synthesis of cyclic carbamates from amino alcohols $\dagger$}

\author{
Teemu Niemi, ${ }^{a}$ Israel Fernández, (D) *b Bethany Steadman, ${ }^{a}$ Jere K. Mannisto ${ }^{a}$ and \\ Timo Repo iD *a
}

\begin{abstract}
We report herein a straightforward general method for the synthesis of cyclic carbamates from amino alcohols and carbon dioxide in the presence of an external base and a hydroxyl group activating reagent. Utilizing $p$-toluenesulfonyl chloride $(\mathrm{TsCl})$, the reaction proceeds under mild conditions, and the approach is fully applicable to the preparation of various high value-added 5- and 6-membered rings as well as bicyclic fused ring carbamates. DFT calculations and experimental results indicate a $\mathrm{S}_{\mathrm{N}}$ 2-type reaction mechanism with high regio-, chemo-, and stereoselectivity.
\end{abstract}

Cyclic carbamate core structures are present in a plethora of valuable chemicals. In particular, 2-oxazolidinones are found in chiral auxiliaries (with 4-substitution) and in superantibiotics such as Linezolid and Tedizolid (with 3-aryl,5-alkyl substitution pattern), whereas aryl-fused 6-membered rings are present in some HIV-battling antiretrovirals and $N$-methyl-D-aspartate (NMDA) receptor antagonists. ${ }^{1-5}$ These compounds are commonly synthesized by utilizing hazardous or expensive reagents such as isocyanides and phosgene. ${ }^{1,4,6,7}$ As such, the replacement of these starting materials with the relatively cheap and safer carbon dioxide offers a unique opportunity to enhance the sustainability and greenness of the synthesis of these high value-added chemicals.

Several strategies for $\mathrm{CO}_{2}$-based preparation of cyclic carbamates have been reported, such as $\mathrm{CO}_{2}$ 's cycloaddition to aziridines, oxetanes, or amino epoxides, ${ }^{8-12}$ and the transesterification of amines with cyclic organic carbonates, which are formed in situ in the cycloaddition of carbon dioxide and epoxides. ${ }^{13,14}$ More recently, approaches utilizing the addition of $\mathrm{CO}_{2}$ to acyclic unsaturated compounds such as alkenes,

\footnotetext{
${ }^{a}$ Department of Chemistry, University of Helsinki, P.O. Box 55, 00014, Finland. E-mail: timo.repo@helsinki.fi

${ }^{b}$ Departamento de Quimica Orgánica I and Centro de Innovación en Química Avanzada (ORFEO-CINQA), Facultad de Ciencias Químicas,

Universidad Complutense de Madrid, Ciudad Universitaria, 28040 Madrid, Spain. E-mail: israel@quim.ucm.es

$\dagger$ Electronic supplementary information (ESI) available: Experimental and computational details, spectroscopic data. See DOI: 10.1039/c8cc00636a
}

alkynes, and propargylic amines or alcohols, have garnered attention. ${ }^{15-26}$ Meanwhile, our group has studied the synthesis of cyclic carbamates utilizing haloalkylamines, ${ }^{27}$ and the multicomponent reaction between anilines, dihaloalkanes, and carbon dioxide. ${ }^{28}$ While certainly more efficient than conventional non$\mathrm{CO}_{2}$-based carbamate syntheses, all these methods have one or more drawbacks, namely the lack of stereoselectivity, ${ }^{29}$ toxicity, and commercial unavailability of the starting materials, or the inability to easily access the substitution patterns required for pharmaceuticals.

Amino alcohols (AAs) are often seen as ideal nitrogen sources in the synthesis of cyclic carbamates from $\mathrm{CO}_{2}$ due to their inexpensiveness, nontoxicity, and ready accessibility. However, the cyclization of AAs with carbon dioxide usually requires high temperatures and pressures even when catalysts, dehydrating agents, or electrochemical methods are employed. ${ }^{8,30-40}$ As a result of these harsh conditions, side reactions (such as a second dehydration to yield the corresponding cyclic urea) are commonplace. $^{30,32,34,35,41}$ Furthermore, previous reports are mainly limited to the synthesis of alkyl substituted oxazolidinones, and additional functionalization is required to prepare high value-added chemicals.

Herein, we present the synthesis of cyclic carbamates from carbon dioxide and amino alcohols. Utilizing $p$-toluenesulfonyl chloride ( $\mathrm{TsCl}$ ) as an activating reagent, the reaction proceeds under mild conditions with good yields and high enantiomeric excess, giving 2-oxazolidinones with the 3-aryl-5-alkyl substitution pattern desired for pharmaceutical applications in a single step. This straightforward method offers predictable regio-, chemo-, and stereoselectivity, and the scope is expandable to the syntheses of 6-membered rings and fused bicyclic compounds, making the process unprecedently versatile. In addition, the reaction mechanism was elucidated by DFT calculations.

Our one-pot approach involves the formation of a carbamate salt from $\mathrm{CO}_{2}$ and AAs in the presence of an external base, followed by the tosylation of the alcohol group to improve its leaving group character, and the subsequent ring-closing via intramolecular substitution (Fig. 1). ROH-tosylation has been 


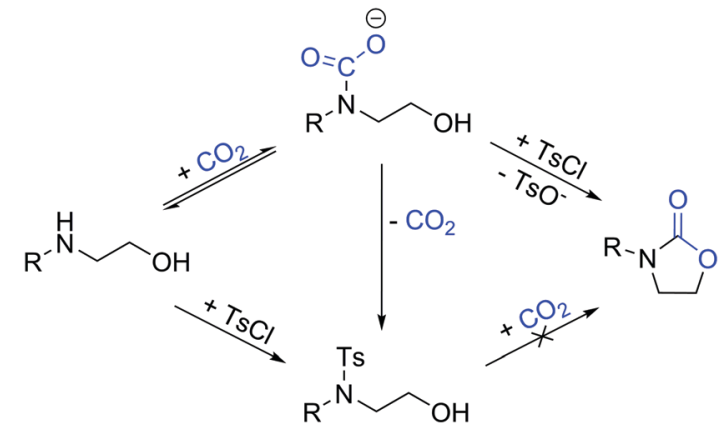

Fig. 1 Tosyl-assisted cyclization of carbon dioxide and amino alcohols in the presence of an external base. The carbamate species must be formed first and stabilized to avoid the competing $N$-tosylation reaction, which prevents the formation of the desired product.

previously employed in the synthesis of cyclic carbonates from 1,3-diols; ${ }^{42}$ here, however, our obvious challenge is the competing $\mathrm{N}$-tosylation reaction, which also prevents the formation of the carbamate moiety and subsequently inhibits the cyclization reaction. Thus, we started our study by finding the optimal reaction conditions in which the formation of the $N$-tosylated product is minimized (Table 1 ). Using the simple, inexpensive and commercially available 2-(phenylamino)ethan-1-ol 1a as a model substrate, we first investigated the reaction conditions we had previously employed successfully in the synthesis of $\mathrm{N}$-aryl-2-oxazolidinones from anilines and dibromoalkanes (Table 1 , entry 1). ${ }^{28}$ However, $N$-tosylation is heavily favored under these conditions, as the carbamate species is too labile to sufficiently protect the nitrogen from a reaction with TsCl. Indeed, decreasing the temperature and increasing the $\mathrm{CO}_{2}$ pressure to shift the equilibrium towards carbamate formation (Table 1, entry 2) leads to a clear increase in selectivity. Lowering the temperature or raising the pressure any further gives no significant improvement, so the rest of the experiments were conducted at RT and 5 bar $\mathrm{CO}_{2}$.

Next, we screened different combinations of solvents and bases. Polar protic solvents (e.g. Table 1, entry 3 ) react with TsCl

Table 1 Reaction condition optimization for maximum selectivity towards 2 a

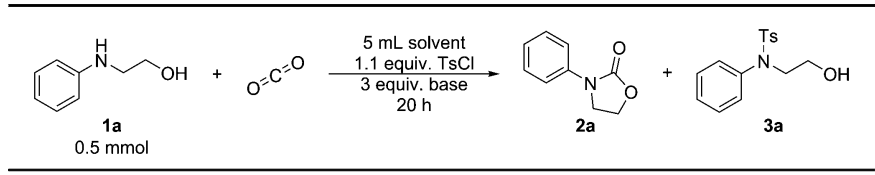

\begin{tabular}{|c|c|c|c|c|c|c|}
\hline Entry & Solvent & Base & $p$ (bar) & $T\left({ }^{\circ} \mathrm{C}\right)$ & Conversion $^{a}(\%)$ & Selectivity $^{b}(\%)$ \\
\hline 1 & $\mathrm{MeCN}$ & $\mathrm{Cs}_{2} \mathrm{CO}_{3}$ & 1 & 60 & 72 & 16 \\
\hline 2 & $\mathrm{MeCN}$ & $\mathrm{Cs}_{2} \mathrm{CO}_{3}$ & 5 & RT & 41 & 65 \\
\hline 3 & EtOH & $\mathrm{Cs}_{2} \mathrm{CO}_{3}$ & 5 & $\mathrm{RT}$ & 25 & 92 \\
\hline 4 & DCM & $\mathrm{Cs}_{2} \mathrm{CO}_{3}$ & 5 & $\mathrm{RT}$ & 5 & 70 \\
\hline 5 & DMF & $\mathrm{Cs}_{2} \mathrm{CO}_{3}$ & 5 & RT & 10 & 100 \\
\hline 6 & Acetone & $\mathrm{Cs}_{2} \mathrm{CO}_{3}$ & 5 & RT & 50 & 100 \\
\hline 7 & Acetone & $\mathrm{Et}_{3} \mathrm{~N}$ & 5 & RT & 18 & 47 \\
\hline 8 & Acetone & $\mathrm{TMG}^{c}$ & 5 & $\mathrm{RT}$ & 17 & 100 \\
\hline 9 & Acetone & $\mathrm{KOH}$ & 5 & $\mathrm{RT}$ & 12 & 14 \\
\hline 10 & Acetone & $\mathrm{K}_{2} \mathrm{CO}_{3}$ & 5 & RT & 27 & 40 \\
\hline
\end{tabular}

${ }^{a}$ Based on total GC yield of $2 \mathbf{a}$ and 3a with mesitylene as external standard. ${ }^{b}$ Defined as yield(2a)/yield(2a $\left.+3 \mathbf{3 a}\right) .{ }^{c}$ TMG $=1,1,3,3$-tetramethylguanidine. and are thus not suitable for this reaction, while nonpolar solvents are not capable of solvating all the reagents and, as a result, generally give poor conversions (e.g. Table 1, entry 4). Polar aprotic solvents were found to offer the highest selectivity towards 2 a, with acetone also significantly enhancing the total conversion (Table 1 , entry 6 ).

Among the Brønstedt bases screened, $\mathrm{Cs}_{2} \mathrm{CO}_{3}$ proved to be the most efficient. $\mathrm{Et}_{3} \mathrm{~N}$ (Table 1, entry 7), which is commonly used in sulfonation reactions shows here low reactivity and poor selectivity. Like protic solvents, even slightly nucleophilic bases such as 1,1,3,3-tetramethylguanidine (TMG), and $\mathrm{KOH}$ (Table 1, entries 8 and 9) favor the reaction with the sulfonating agent, therefore leading to low conversion of 1a. Finally, other carbonate bases (Table 1, entry 10) are inferior to $\mathrm{Cs}_{2} \mathrm{CO}_{3}$ due to their lower solubility in the reaction medium. Thus, the highest conversion accompanied with good selectivity is achieved when the reaction is carried out in acetone under 5 bar $\mathrm{CO}_{2}$ at room temperature, with $\mathrm{Cs}_{2} \mathrm{CO}_{3}$ as the base (Table 1, entry 6).

With amino alcohols where the $\mathrm{OH}$ group is primary, the reaction stops at $50 \%$ very likely due to the formation of a salt between the ionic byproducts, the remaining starting material, and possibly carbon dioxide. Although the exact composition of this salt was not elucidated, the remaining amino alcohol can be quantitatively recovered upon dissolving the solid reaction phase into $\mathrm{H}_{2} \mathrm{O}$, indicating that a reversible salt-forming reaction indeed takes place. Attempts to overcome this plateau by increasing base loading or $\mathrm{CO}_{2}$ pressure were not successful.

As we turned our attention to other substrates (Fig. 2), we discovered that amino alcohols with secondary hydroxyl groups are more reactive, as $\mathbf{2 b}$ was isolated in $\mathbf{8 3} \%$ yield, which is only slightly lower than what is achieved with isocyanate-based methods. ${ }^{43,44}$ Tertiary hydroxyl groups, meanwhile, are sterically too hindered to readily undergo cyclization, and a significant decrease in yield is observed for 2c. In the synthesis of carbamate 6-membered rings from the corresponding amino propanols, a similar trend can be seen: the formation of 6-ring $\mathbf{4 a}$ from the commercially available 3-(phenylamino)propan-1-ol stops at $50 \%$, while a more substituted amino alcohol yields $57 \%$ of $\mathbf{4 b}$. Attempts to prepare larger 7- or 8-membered rings were not successful.

Aromatic ring substituents affect the reaction outcome, as well. The presence of a weakly activating alkyl group leads
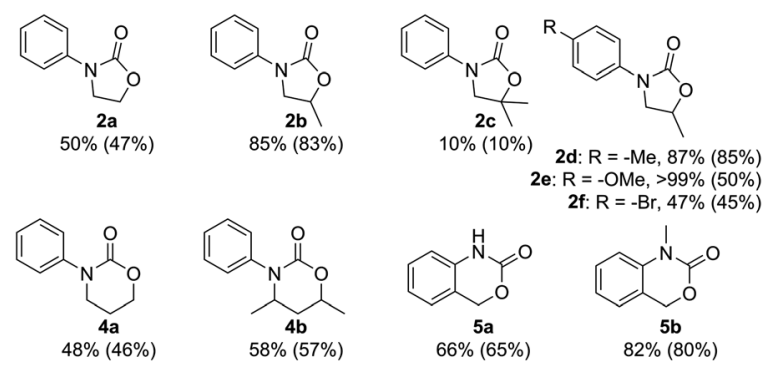

2f: $R=-B r, 47 \%(45 \%)$

Fig. 2 Conversions of various amino alcohols and the isolated yields (in parentheses) of the corresponding cyclic carbamates. Reaction conditions: amino alcohol 1 ( $0.5 \mathrm{mmol}$ ), $\mathrm{TsCl}$ (1.1 equiv.), $\mathrm{Cs}_{2} \mathrm{CO}_{3}$ (3 equiv.), $\mathrm{CO}_{2}$ (5 bar), acetone $(5 \mathrm{~mL})$, room temperature, $20 \mathrm{~h}$. 
to the slightly enhanced yield observed for $\mathbf{2 d}$, whereas the more strongly activating alkoxy moiety affords quantitative conversion at the cost of selectivity, and $\mathbf{2 e}$ and the corresponding $N$-tosylated amino alcohol are isolated in a $c a$. 1:1 ratio. This marks the only occasion in which any $N$-tosylation was detected under the optimized reaction conditions. A deactivating halogen substituent, meanwhile, leads to a decrease in conversion, but full selectivity is maintained in the synthesis of $\mathbf{2 f}$.

The reaction can also be extended to the synthesis of fused rings 5 from 2-aminobenzyl alcohols with yields up to $80 \%$. Like $N$-aryl-2-oxazolidinones, these structures are omnipresent in pharmaceuticals, and can be found, for instance, in Efavirenz, an antiretroviral used to treat $\mathrm{HIV}^{4}$ and in NMDA receptor antagonists, useful for treating stroke, cerebral ischemia, and depression. ${ }^{5}$ To our knowledge, the present work represents the first example of a $\mathrm{CO}_{2}$-based synthesis of these compounds, and is in fact as efficient as the phosgene-based method. ${ }^{45}$

To further establish the generality and applicability of this methodology in synthesis, we probed the chemo- and stereoselectivity of the reaction by screening difunctionalized and enantiopure amino alcohols as starting materials (Fig. 3). We have previously shown that the cyclization of carbon dioxide and 2,3-dichloropropan-1-amine strongly favors the formation of the more stable 5-ring ( $81 \%$-ring, $17 \%$ 6-ring): ${ }^{27} \mathbf{1 i}$, on the other hand, gives a mixture of the two possible products in a ca. 5:6 ratio, as the thermodynamic stability of the 5-ring is offset by the better leaving group nature of the $-\mathrm{Cl}$. The easily synthesizable amino diol $\mathbf{1 j}$, meanwhile, expectedly shows preference towards the formation of the 5 -ring $\mathbf{2 h}$, which can be isolated in $85 \%$ yield, and intriguingly with a higher selectivity towards the 5-ring than when the dihaloalkylamine was employed.

As we envision our method applicable to the synthesis of pharmaceutical compounds and chiral auxiliaries, predictable stereochemistry is of utmost importance. To our delight, the reaction also proceeds with high stereoselectivity, and $>99 \%$ ee is observed for most substrates. In fact, only the amino diol $\mathbf{1 l}$ undergoes some racemization, but the corresponding oxazolidinone $2 \mathrm{j}$ is still isolated in a good yield and $90 \%$ ee. The products have inverted configuration at the stereocenter, which hints at a $\mathrm{S}_{\mathrm{N}} 2$-type mechanism during the ring-closing step. To shed some

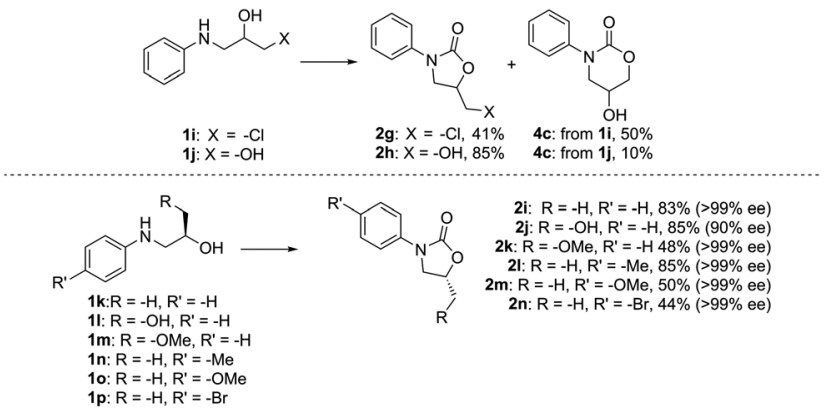

Fig. 3 Chemo- and stereoselectivity of the reaction. All yields are isolated yields. Reaction conditions: amino alcohol 1 ( $0.5 \mathrm{mmol}), \mathrm{TsCl}$ (1.1 equiv.), $\mathrm{Cs}_{2} \mathrm{CO}_{3}$ (3 equiv.), $\mathrm{CO}_{2}$ (5 bar), acetone $(5 \mathrm{~mL})$, room temperature, $20 \mathrm{~h}$. further light on the involved reaction mechanism, the transformation was next studied in silico.

The computed reaction profile for the reaction of the parent amino alcohol 1a and $\mathrm{CO}_{2}$ in the presence of mesylchloride (MsCl), as a model of the experimentally used TsCl, is shown in Fig. 4, which gathers the corresponding relative Gibbs free energies $\left(\Delta G_{298}\right.$, at $\left.298 \mathrm{~K}\right)$ in acetone computed at the PCM(acetone)M062X/def2-TZVPP//PCM(acetone)-M062X/6-31+G(d) level. ${ }^{46}$ Our DFT calculations indicate that the process begins with the formation of zwitterionic intermediate INT1 via transition state TS1, a saddle point associated with the nucleophilic attack of the amino group of $1 \mathrm{a}$ to the electrophilic $\mathrm{CO}_{2}$. The alternative reaction of $1 \mathrm{a}$ with the activating agent $\mathrm{MsCl}$, leading to INT1' via TS1', is not competitive in view of the much higher activation barrier $\left(\Delta \Delta G^{\ddagger}=12.8 \mathrm{kcal} \mathrm{mol}^{-1}\right)$ and endergonicity $\left(\Delta \Delta G_{\mathrm{R}}=11.4 \mathrm{kcal} \mathrm{mol}^{-1}\right)$ associated with this process, which is fully consistent with the complete regioselectivity observed for the transformation (see above). Although the formation of INT1

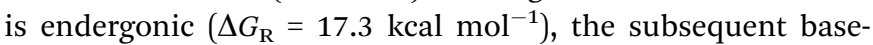
mediated deprotonation of this species is highly exergonic $\left(\Delta G_{\mathrm{R}}=-46.2 \mathrm{kcal} \mathrm{mol}^{-1}\right)$ and drives the transformation forward. This step leads to the formation of the highly stabilized anionic intermediate INT2, which readily reacts with $\mathrm{MsCl}$ to produce, in an exergonic process $\left(\Delta G_{\mathrm{R}}=-3.2 \mathrm{kcal} \mathrm{mol}^{-1}\right)$, the corresponding mesyl derivative INT3. This step occurs via TS2 (activation barrier of $21.4 \mathrm{kcal} \mathrm{mol}^{-1}$ ) in a typical $\mathrm{S}_{\mathrm{N}} 2$ reaction thus releasing $\mathrm{HCl}$, which is then neutralized by the excess of base. The transformation ends up with the formation of the experimentally observed carbamate 2a via TS3 in a highly exergonic process $\left(\Delta G_{\mathrm{R}}=-30.1 \mathrm{kcal} \mathrm{mol}^{-1}\right)$ with a reaction barrier of $18.1 \mathrm{kcal} \mathrm{mol}^{-1}$ (fully compatible with a process occurring at room temperature). This saddle point is associated with the intermolecular synchronous displacement of the OMs leaving group by the nucleophilic $(\mathrm{O}=) \mathrm{CO}^{-}$moiety of INT3, thus forming the new $\mathrm{C}-\mathrm{O}$ bond of the carbamate. According to the

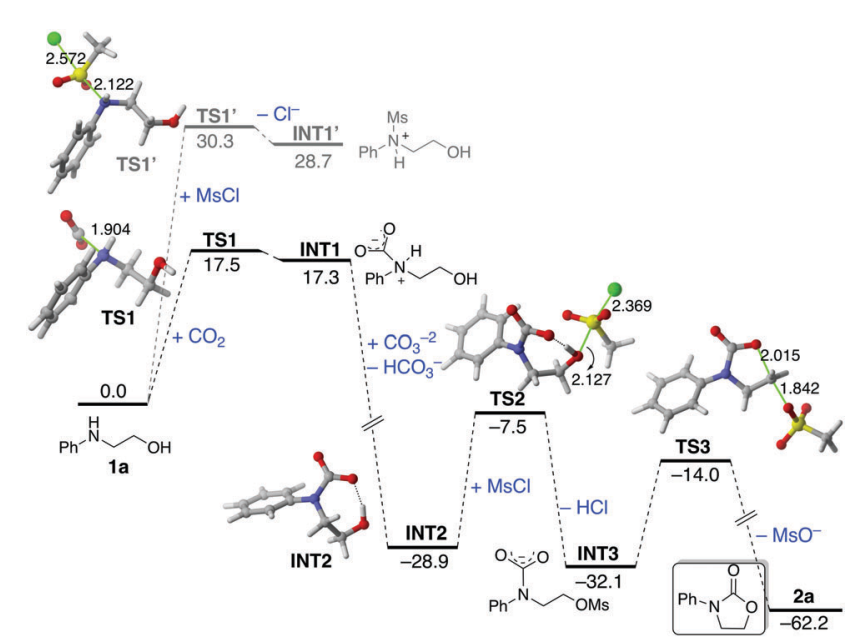

Fig. 4 Computed reaction profile for the reaction of amino alcohol 1a and $\mathrm{CO}_{2}$ in the presence of $\mathrm{MsCl}$. Relative Gibbs free energies and bond distances are given in $\mathrm{kcal} \mathrm{mol}^{-1}$ and angstroms, respectively. All data have been computed at the PCM(acetone)-M062X/def2-TZVPP//PCM(acetone)M062X/6-31+G(d) level. 
geometry of TS3, this final ring closure can be viewed as an intramolecular backside $\mathrm{S}_{\mathrm{N}} 2$ reaction, which nicely agrees with the inversion of configuration observed in the processes involving the chiral substrates 1k-p (see Fig. 3).

In conclusion, we have developed a facile and general method for the stereoselective synthesis of cyclic carbamates from carbon dioxide and amino alcohols. The reaction is applicable to the preparation of 3-aryl,5-alkyl substituted 2-oxazolidinones found in Linezolid and other superantibiotics, cyclic fused rings found in antiretrovirals and NMDA receptor antagonists, as well as 6-membered rings. Under the optimized reaction conditions, the process has high regio-, chemo-, and stereoselectivity. Enantiopure amino alcohols undergo inversion of configuration at the stereocenter, which hints at a $\mathrm{S}_{\mathrm{N}} 2$-type reaction mechanism during the key ring-closing step; this observation was later supported by DFT calculations.

This work was partially funded by the Academy of Finland (project \#310767). TN is grateful for the University of Helsinki’s doctoral programme in chemistry and molecular sciences (CHEMS) for funding. IF acknowledges financial support from the Spanish MINECO-FEDER (Grants CTQ2016-78205-P and CTQ2016-81797-REDC).

\section{Conflicts of interest}

There are no conflicts to declare.

\section{Notes and references}

1 S. J. Brickner, Curr. Pharm. Des., 1996, 2, 175-194.

2 H. Ucar, K. Van derpoorten, S. Cacciaguerra, S. Spampinato, J. P. Stables, P. Depovere, M. Isa, B. Masereel, J. Delarge and J. H. Poupaert, J. Med. Chem., 1998, 41, 1138-1145.

3 R. Schaadt, D. Sweeney, D. Shinabarger and G. Zurenko, Antimicrob. Agents Chemother., 2009, 53, 3236-3239.

4 V. Famiglini and R. Silvestri, Molecules, 2016, 21, 1-18.

5 Y. Chen, C. A. Hone, B. Gutmann and C. O. Kappe, Org. Process Res. Dev., 2017, 21, 1080-1087.

6 M. S. Newman and A. Kutner, J. Am. Chem. Soc., 1951, 73, 4199-4204.

7 M. E. Dyen and D. Swern, Chem. Rev., 1967, 67, 197-246.

8 P. Tascedda and E. Dunach, Chem. Commun., 2000, 449-450.

9 J. Rintjema, W. Guo, E. Martin, E. C. Escudero-Adán and A. W. Kleij, Chem. - Eur. J., 2015, 21, 10754-10762.

10 V. B. Saptal and B. M. Bhanage, ChemSusChem, 2016, 9, 1980-1985.

11 H. Wang, J. C. Yang and S. L. Buchwald, J. Am. Chem. Soc., 2017, 139, 8428-8431.

12 J. Rintjema, R. Epping, G. Fiorani, E. Martín, E. C. Escudero-Adán and A. W. Kleij, Angew. Chem., Int. Ed., 2016, 55, 3972-3976.

13 B. Wang, E. H. M. Elageed, D. Zhang, S. Yang, S. Wu, G. Zhang and G. Gao, ChemCatChem, 2014, 6, 278-283.

14 U. R. Seo and Y. K. Chung, Green Chem., 2017, 19, 803-808.
15 W.-Z. Zhang, X. Ren and X.-B. Lu, Chin. J. Chem., 2015, 33, 610-613.

16 B.-B. Cheng, B. Yu and C.-W. Hu, RSC Adv., 2016, 6, 87179-87187.

17 K.-i. Fujita, A. Fujii, J. Sato, S.-y. Onozawa and H. Yasuda, Tetrahedron Lett., 2016, 57, 1282-1284.

18 H. Liu and R. Hua, Tetrahedron, 2016, 72, 1200-1204.

19 Q.-W. Song, Z.-H. Zhou, M.-Y. Wang, K. Zhang, P. Liu, J.-Y. Xun and L.-N. He, ChemSusChem, 2016, 9, 2054-2058.

20 B. Yu, B.-B. Cheng, W.-Q. Liu, W. Li, S.-S. Wang, J. Cao and C.-W. Hu, Adv. Synth. Catal., 2016, 358, 90-97.

21 P. Brunel, J. Monot, C. E. Kefalidis, L. Maron, B. Martin-Vaca and D. Bourissou, ACS Catal., 2017, 7, 2652-2660.

22 X. Liu, M.-Y. Wang, S.-Y. Wang, Q. Wang and L.-N. He, ChemSusChem, 2017, 10, 1210-1216.

23 M.-Y. Wang, Y. Cao, X. Liu, N. Wang, L.-N. He and S.-H. Li, Green Chem., 2017, 19, 1240-1244.

24 B. Yu, D. Kim, S. Kim and S. H. Hong, ChemSusChem, 2017, 10, 1080-1084.

25 P. H. Dixneuf, Catal. Lett., 2015, 145, 360-372.

26 J. Fournier, C. Bruneau and P. H. Dixneuf, Tetrahedron Lett., 1990, 31, 1721-1722.

27 T. Niemi, J. E. Perea-Buceta, I. Fernández, S. Alakurtti, E. Rantala and T. Repo, Chem. - Eur. J., 2014, 20, 8867-8871.

28 T. Niemi, J. E. Perea-Buceta, I. Fernández, O.-M. Hiltunen, V. Salo, S. Rautiainen, M. T. Räisänen and T. Repo, Chem. - Eur. J., 2016, 22, 10355-10359.

29 J. Vaitla, Y. Guttormsen, J. K. Mannisto, A. Nova, T. Repo, A. Bayer and K. H. Hopmann, ACS Catal., 2017, 7, 7231-7244.

30 E. S. Streng, D. S. Lee, M. W. George and M. Poliakoff, Beilstein J. Org. Chem., 2017, 13, 329-337.

31 S. W. Foo, Y. Takada, Y. Yamazaki and S. Saito, Tetrahedron Lett., $2013,54,4717-4720$.

32 M. Tamura, M. Honda, K. Noro, Y. Nakagawa and K. Tomishige, J. Catal., 2013, 305, 191-203.

33 M. Kodaka, T. Tomohiro and H. Okuno, J. Chem. Soc., Chem. Commun., 1993, 81-82.

34 S.-I. Fujita, H. Kanamaru, H. Senboku and M. Arai, Int. J. Mol. Sci., 2006, 7, 438.

35 S. Pulla, C. M. Felton, Y. Gartia, P. Ramidi and A. Ghosh, ACS Sustainable Chem. Eng., 2013, 1, 309-312.

36 Y. P. Patil, P. J. Tambade, S. R. Jagtap and B. M. Bhanage, J. Mol. Catal. A: Chem., 2008, 289, 14-21.

37 M. Feroci, M. Orsini, G. Sotgiu, L. Rossi and A. Inesi, J. Org. Chem., 2005, 70, 7795-7798.

38 M. A. Casadei, F. M. Moracci, G. Zappia, A. Inesi and L. Rossi, J. Org. Chem., 1997, 62, 6754-6759.

39 B. R. Buckley, A. P. Patel and K. G. U. Wijayantha, Synlett, 2014, 197-200.

40 M. Feroci, A. Gennaro, A. Inesi, M. Orsini and L. Palombi, Tetrahedron Lett., 2002, 43, 5863-5865.

41 B. M. Bhanage, S.-i. Fujita, Y. Ikushima and M. Arai, Green Chem., 2003, 5, 340-342.

42 G. L. Gregory, M. Ulmann and A. Buchard, RSC Adv., 2015, 5, 39404-39408.

43 R. L. Paddock, D. Adhikari, R. L. Lord, M.-H. Baik and S. T. Nguyen, Chem. Commun., 2014, 50, 15187-15190.

44 P. Wang, J. Qin, D. Yuan, Y. Wang and Y. Yao, ChemCatChem, 2015, 7, 1145-1151.

45 G.-J. Griffiths, M. Lorenzi and A. Warm, US 20110172419, 2011.

46 See computational details in the ESI $\dagger$. 